\title{
A Mobile Terminal Leaky-Wave Antenna for Efficient 5G Communication
}

\author{
Youssef El Gholb*(1), Miguel Poveda-Garcia ${ }^{(2)}$, José Luis Gómez Tornero ${ }^{(2)}$, Jose Maria Molina-Garcia- \\ Pardo $^{(2)}$, Najiba El Amrani El Idrissi ${ }^{(1)}$ \\ (1) The University of Sidi Mohamed Ben Abdellah, Fez., Morocco, e-mail: youssef.elgholb@gmail.com; \\ najiba.elamrani@usmba.ac.ma \\ (2) Universidad Politécnica Cartagena, Cartagena, Spain; e-mail: miguel.poveda@upct.es; \\ josel.gomez@upct.es; josemaria.molina@upct.es
}

Keywords: Millimeter wave antenna; 5 G antenna; Dual-band antenna; LWA (Leaky wave antenna)

The millimeter-wave $37-43.5 \mathrm{GHz}$ band is proposed to provide the requested multigigabit-per-second (Gb/s) data rates for future $5 \mathrm{G}$ cellular communications [1]. As a total wireless-link gain of $37 \mathrm{dBi}$ may be required, the mobile terminal antennas should provide $12 \mathrm{dBi}$ gain -being the remaining $25 \mathrm{dBi}$ for the base station antennas-[2] [3]. This high gain is linked to the synthesis of narrow directive radiated beam, which must somehow be scanned into space over a wide field of view (FoV), and thus satisfy the mobility and coverage conditions. Such high-gain beam-scanning antenna design is very challenging, taking into account that high radiation efficiency, compact size/volume, and low-cost are key features for mass-market mm-wave applications. In this sense, most of the proposed 5G mobile-antenna solutions are based on phased arrays, which rely on active scanning/beam-forming networks which might be impractical due to an increase cost and manufacturing complexity. However, owning to their characteristics of high-gain, simple-feeding, planar structure, and inherent frequency-beam-scanning behavior, leaky-wave antennas (LWAs) might offer an interesting solution for high-gain low-cost scanning [4].

In this work, we propose a printed-circuit frequency-scanning LWA topology [4], which is applied for 5G mobile terminals operating in the $38 \mathrm{GHz}$ band $(37-43.5 \mathrm{GHz})$. Despite its totally-passive simple structure using a longmetallic patch fed by two microstrip ports (see Fig.1a), the LWA exhibits frequency-scanning capability in a FoV as wide as $\left[-57^{\circ},+57^{\circ}\right]$ using the recommended four channels in the $37-43.5 \mathrm{GHz}$ band (see Fig. $1 \mathrm{~b}$ ). The designed LWA reports a high radiation efficiency above $85 \%$ in the complete scanning band, using an aperture length of $35.5 \mathrm{~mm}$ and reduced width of $1.41 \mathrm{~mm}$, and producing directive beams exceeding $12 \mathrm{dBi}$ peak gain which is comparable with the array system the $11 \mathrm{dBi}$ of the $3 \mathrm{sub}$ arrays of $1 \mathrm{x} 4$ elements each at $36 \mathrm{GHz}$ [5], and the $10 \mathrm{dBi}$ gain of the $2 \mathrm{sub}$ arrays of $1 \times 16$ elements each at $28 \mathrm{GHz}$ band [6]. The effect of the beam-squint inside the $1 \mathrm{GHz}$ bandwidth associated to each communication channel needs to be evaluated. The proposed simple onedimensional frequency-scanning topology dispenses for more expensive electronic-scanning techniques, provided that the $5 \mathrm{G}$ mobile terminal can use a dynamic channel-allocation scheme when communicating with the cellular base station.

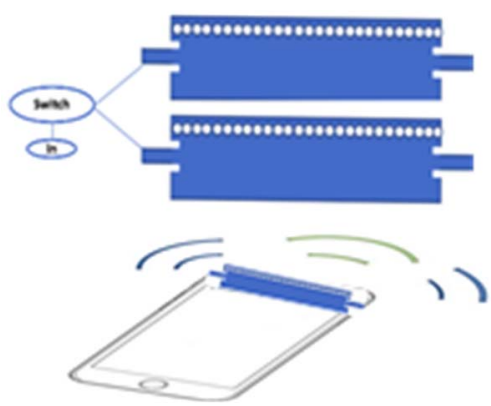

(a)

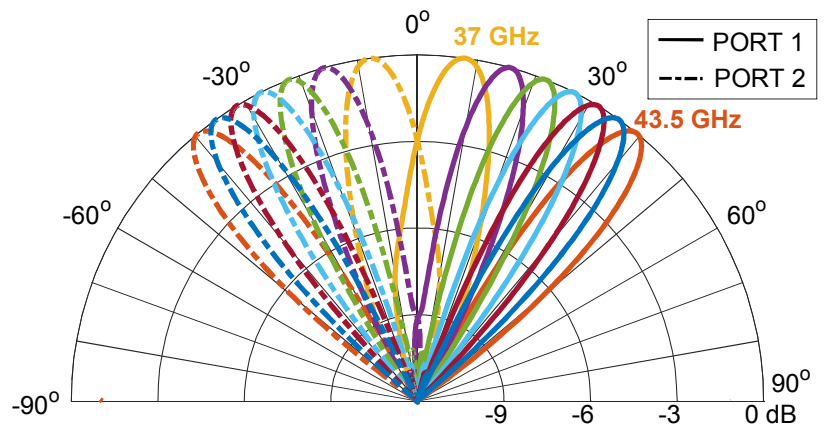

(b)

Figure 1. a) LWA design b) Frequency-scanned radiation using the channels available in the $36-40 \mathrm{GHz}$ band

1. NGMN 5G Spectrum White Paper, August 2018

2. Dupleich, Diego, et al. "A Hybrid Polarimetric Wide-Band Beamformer Architecture for 5G mm-Wave Communications." Smart Antennas (WSA 2016); Proceedings of the 20th International ITG Workshop on. VDE, 2016.

3. Psychoudakis, D., Zhou, H., Biglarbegian, B., Henige, T. and Aryanfar, F., 2016, May. Mobile station radio frequency unit for $5 \mathrm{G}$ communications at 28GHz. IEEE MTT-S International, pp. 1-3, 2016

4. Zelenchuk, Dmitry, et al. "W-band planar wide-angle scanning antenna architecture." Journal of Infrared, Millimeter, and Terahertz Waves 34.2 (2013): 127-139.

5. Hong, W.; Baek, K.H.; Lee, Y.; Kim, Y.; Ko, S.T. Study and prototyping of practically large-scale mmWave antenna systems for 5G cellular devices. IEEE Commun. Mag. 2014, 52, 63-69

6. Hsu, Y.W.; Huang, T.C.; Lin, H.S.; Lin, Y.C. Dual-Polarized Quasi Yagi-Uda Antennas with Endfire Radiation for Millimeter-Wave MIMO Terminals. IEEE Trans. Antennas Propag. 2017, 65, 6282-6289 